\title{
Evaluating the effectiveness of Sunnyside Gold Corporation's reclamation, San Juan County, Colorado, USA
}

\author{
S Lange Knight Piésold and Co., USA
}

\begin{abstract}
The Animas River in the area around Silverton, San Juan County, Colorado has been adversely impacted by high loading of iron, aluminium, cadmium, copper, lead, zinc, arsenic, and nickel. Metals loading in the Animas River has limited aquatic life, including the trout fishery downstream from Silverton. The metals concentrations in the Animas River is due to acid rock drainage formed from a combination of natural weathering of mineralised rocks and residues from over 100 years of historic mining. Sunnyside Gold Corporation (SGC) was formed and acquired the Sunnyside Mine in the Upper Animas basin in 1985. SGC operated the mine from 1986 until 1991 using modern techniques and under strict environmental regulation, and has engaged in more than 30 years of reclamation and remediation in the Silverton Caldera. This included removal of mine waste from owned and other area mines, treatment of water discharged from mine portals, seasonal treatment of the flow in Cement Creek, installation of bulkheads in mine workings, and stabilisation of tailings deposits. Evaluation of long-term monitoring results demonstrates that SGC's actions have substantially reduced acid rock drainage and metals loading in the Animas River compared to what would have otherwise been the case.
\end{abstract}

Keywords: reclamation, remediation, water quality, metals loading, Animas River, bulkheads

\section{Introduction}

Sunnyside Gold Corporation (SGC) has engaged in over 30 years of reclamation and remediation in and around the Sunnyside Mine near Silverton, Colorado (Figure 1) with the objective of improving water quality and habitats in the Animas River. Some of this work was done pursuant to a voluntary Consent Decree agreement (Consent Decree) with the State of Colorado Department of Public Health and Environment (CDPHE) (Sunnyside Gold Corporation v Colorado Water Quality Control Division of the Colorado Department of Public Health and Environment 1998). SGC was released from liabilities in 2003 after CDPHE employed the methodology set forth in the Consent Decree to analyse metals loading in the Animas River and concluded that SGC had met the target and successfully completed its obligations. This paper evaluates the ongoing success of SGC's activities by analysing 22 years of publicly available data collected at the United States Geological Survey (USGS) gaging station A-72 on the Animas River just downstream from Silverton in accordance with the methodology taken directly from the Consent Decree. A-72 is a long-established monitoring point for Animas River water quality. The large number of samples taken by various entities at A-72 have been utilised in numerous analyses and studies over the years.

The current study comprises a comprehensive analysis of zinc samples from 1996 to present at A-72 pursuant to the CDPHE methodology, with the aim to conclusively demonstrate that bulkheading and remediation conducted by SGC was successful in improving Animas River water quality and that the targets set by CDPHE continue to be met. 


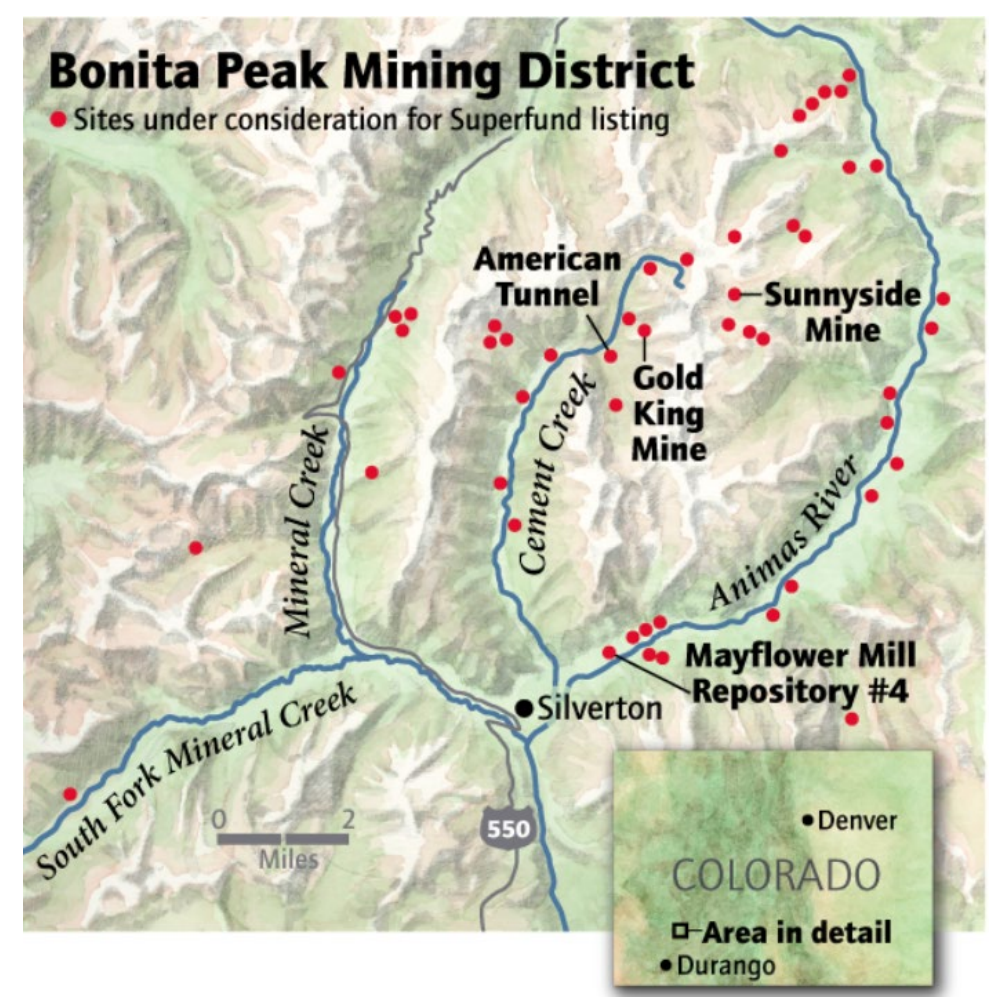

Figure 1 Site location

\section{Background}

The Silverton Caldera is naturally highly mineralised and has been for millions of years, with acid rock drainage and poor water quality prevalent long before the advent of mining. Before the first miner arrived, there was massive natural metals loading in the Animas River which limited aquatic life, including trout populations downstream from Silverton (Besser \& Brumbaugh 2007). Historically, parts of Cement and Mineral Creeks were always acidic, contained high metals loads, and likely did not support any aquatic life other than species of algae that can tolerate a pH $<4$ (Church et al. 2007).

Serious mineral exploration began in the early 1870s and at that time, the Upper Animas watershed became a prime location of mining activity for gold, silver, lead, and copper. The area hosted over 1,500 mines (United States Geological Survey 1999). In addition, the area was home to over 50 separate mill sites, eight distinct smelters, and 35 different aerial trams (Jones 2007). With the arrival of mining in the Upper Animas 140 years ago, drainage from mine adits, discharges of tailings to water ways, and the weathering of waste rock added to the naturally high metal and acid loads in the Animas River and its tributaries. Waste rock was disposed of in waste dumps outside the mine portal and processing wastes were deposited into the nearest stream course. An estimated 8.6 million short tons of mill waste, about $47.5 \%$ of the total ore produced, was discharged directly into surface streams between 1872 and 1935 (Jones 2007; US Geological Survey 2007). Discharges from mining-impacted areas continued long after the mines were no longer active.

Before the 1970s, there were no measurements of any of these discharge quantities, but they were clearly significant. Miners were not required to reclaim their sites until the 1970 s and most followed the acceptable practices of their time.

\section{Sunnyside Gold Corporation activities}

SGC was formed and acquired the Sunnyside Mine in 1985. SGC operated the mine from 1986 until 1991 using modern techniques and under strict environmental regulations. Since 1985, SGC has engaged in over 30 years of reclamation and remediation in the district. In 1996, SGC entered into a Consent Decree with the State of Colorado that was supported by the Animas River Stakeholders Group and the Environmental 
Protection Agency (EPA) with the objective of improving water quality and habitats in the Animas River. Under the Consent Decree, SGC completed numerous activities throughout the district (bulkheading and remediation) designed to improve water quality in the Animas River.

An important element of the state-approved plan was the installation of engineered concrete bulkheads with the primary purpose of isolating the interior workings of the Sunnyside and other mines to prevent water flow from the interior workings to the Animas Basin. Much of the reclamation and remediation work was completed at historical mine sites not owned or disturbed by SGC (Appendix 1).

The success of the approach was evaluated by CDPHE utilising the regression equation (equation 1 ) discussed in Section 5. There were two independent aspects to CDPHE's plan to achieve the target:

1. SGC's bulkheading and remediation.

2. The operation of a water treatment plant at Gladstone.

Each separate aspect was designed to address a portion of the metals loading and improve water quality.

In 2003, SGC was released from liabilities after the work was inspected and approved by the relevant agencies. SGC has also fulfilled all of its regulatory requirements and is in compliance with all of its reclamation obligations. However, monitoring of the surface water at A-72 has continued to the present to validate the continued effectiveness of the reclamation program.

Figures 2-7 present before and after photos of SGC's reclamation activities to illustrate the efficacy of the efforts undertaken to reduce erosion and weathering of mine waste and tailings to decrease the contribution of dissolved and total metals to surface waters in the project area.

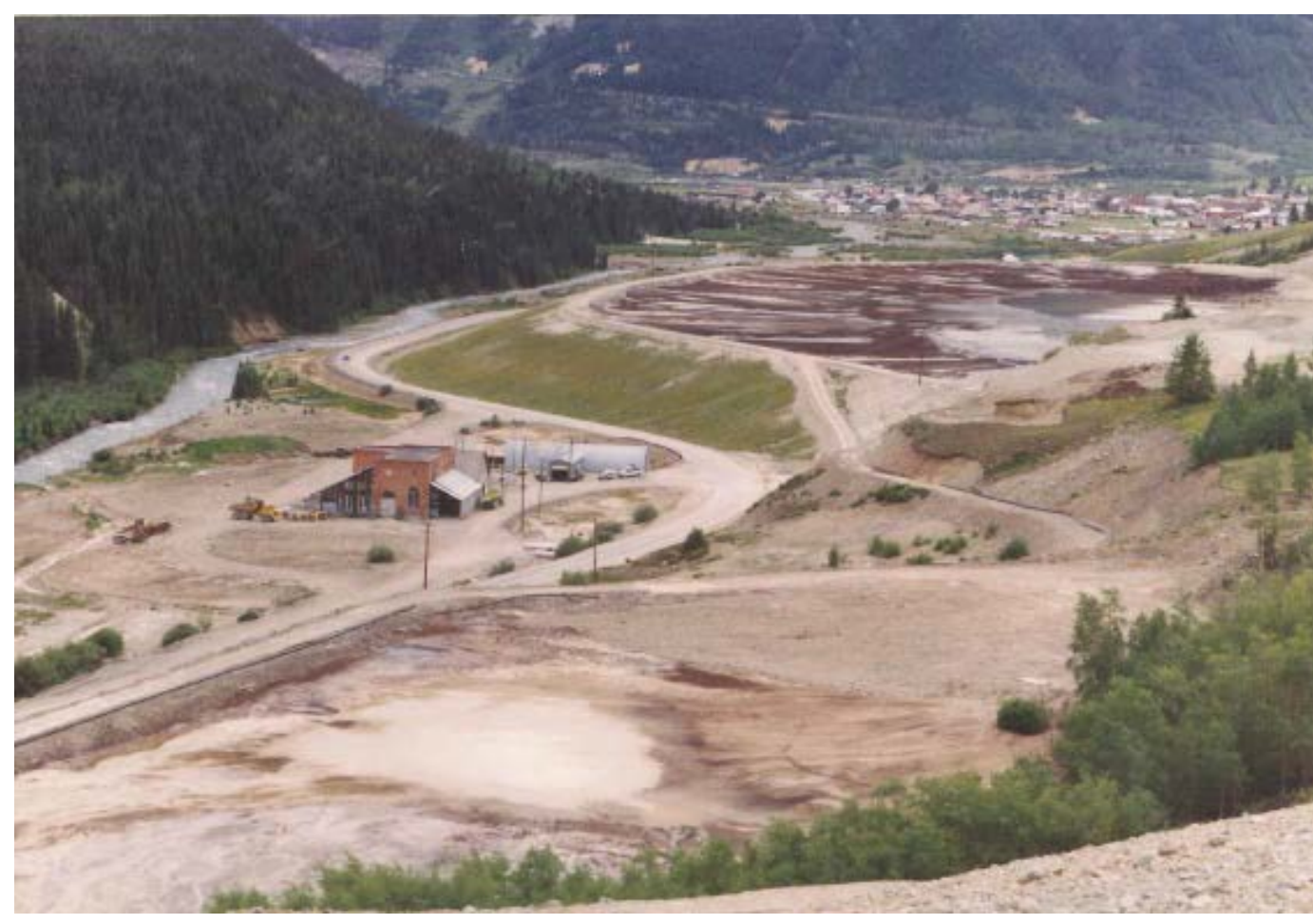

Figure 2 Mayflower tailings ponds 3 and 4, 1992, before reclamation 


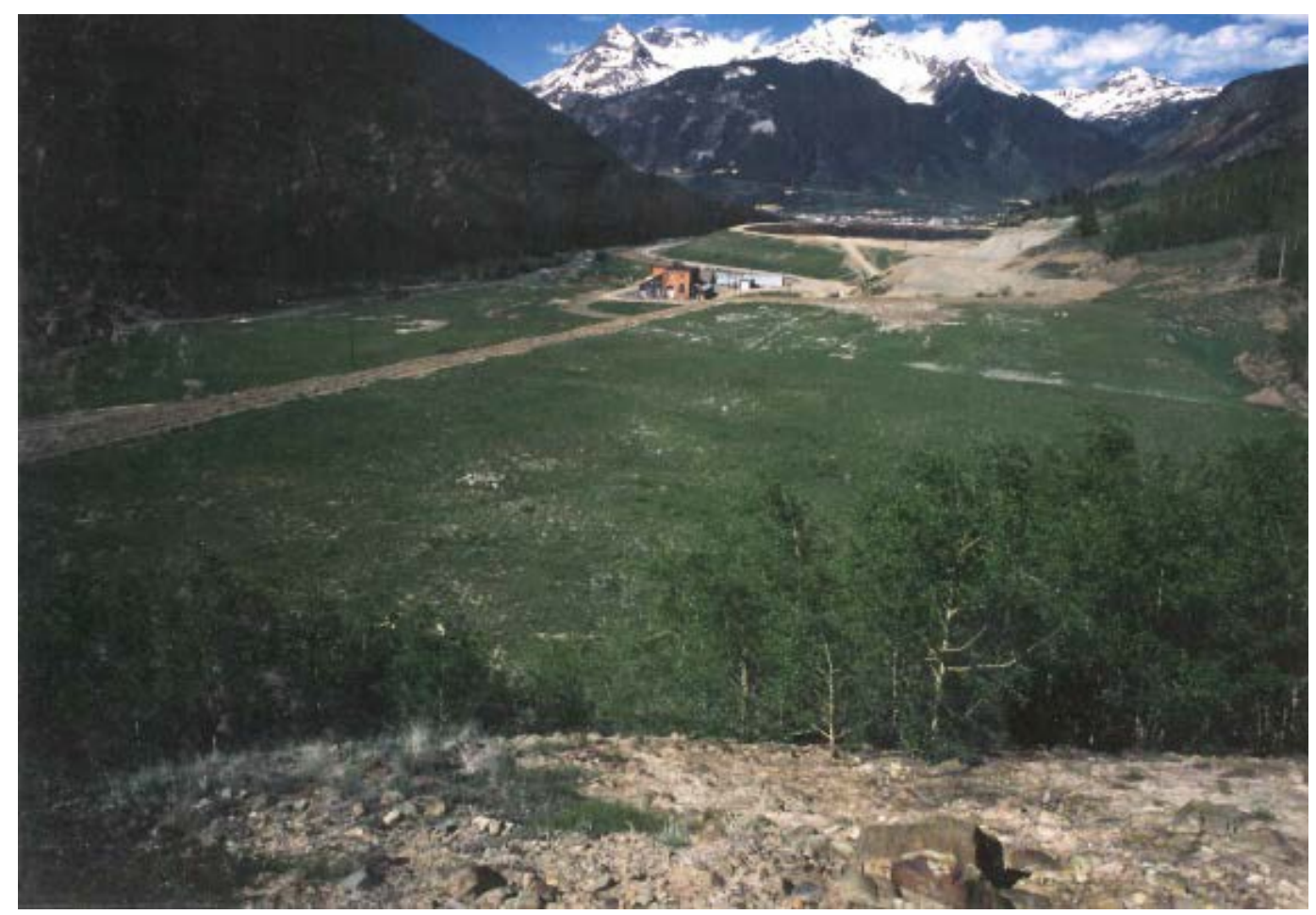

Figure 3 Mayflower tailings ponds 3 and 4, 1995, after reclamation

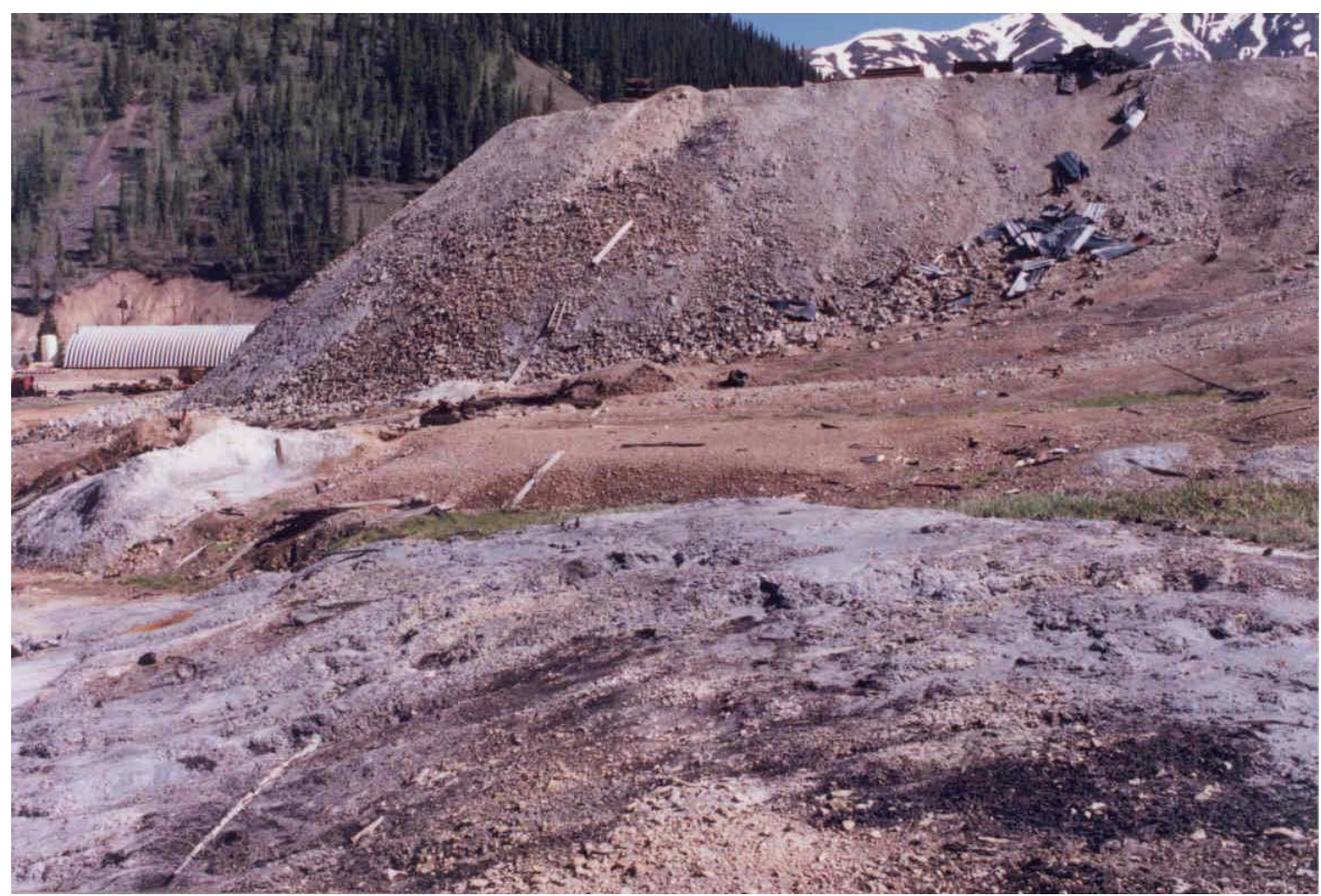

Figure 4 American Tunnel, 1995, before reclamation 


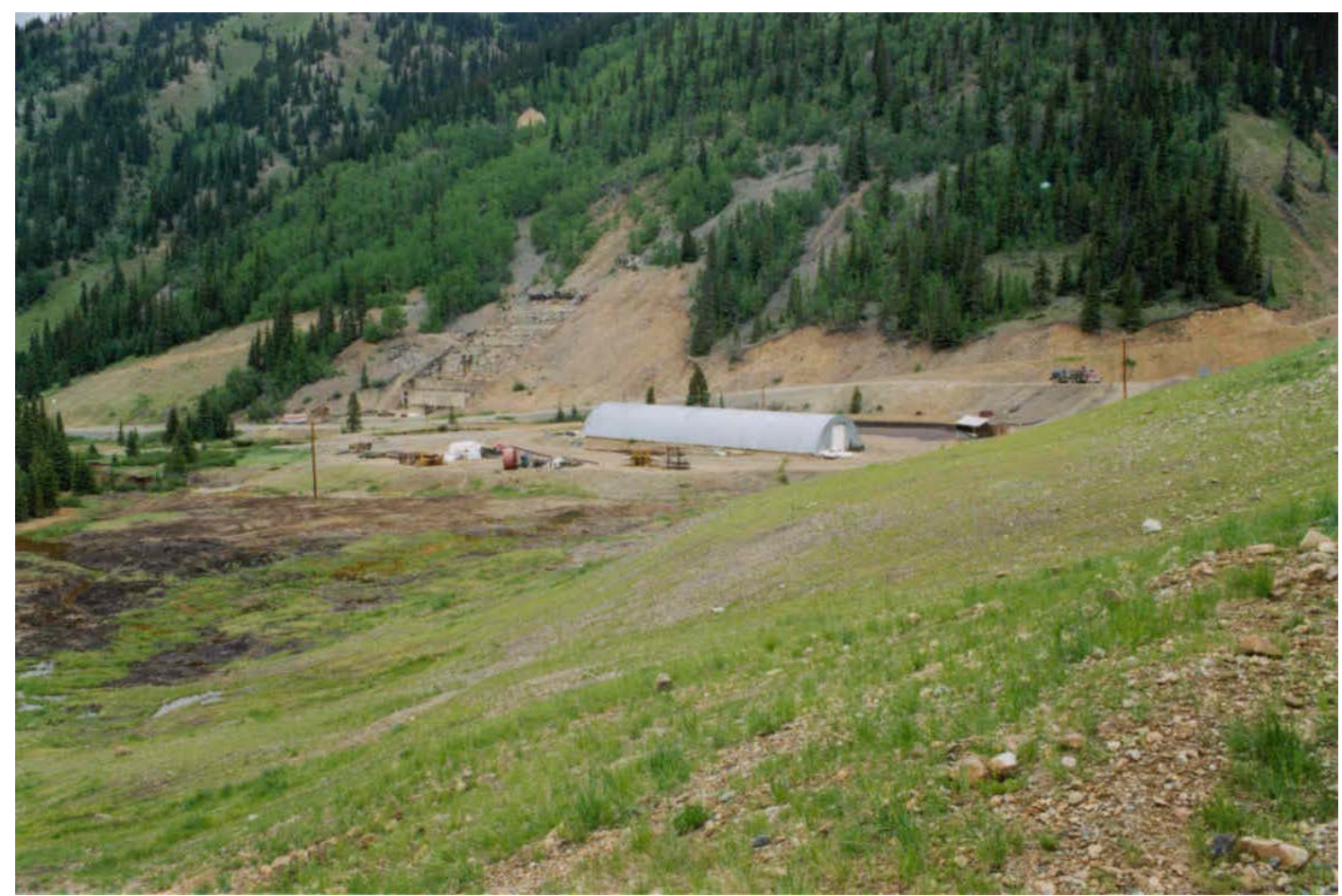

Figure 5 American Tunnel, 1998, after reclamation

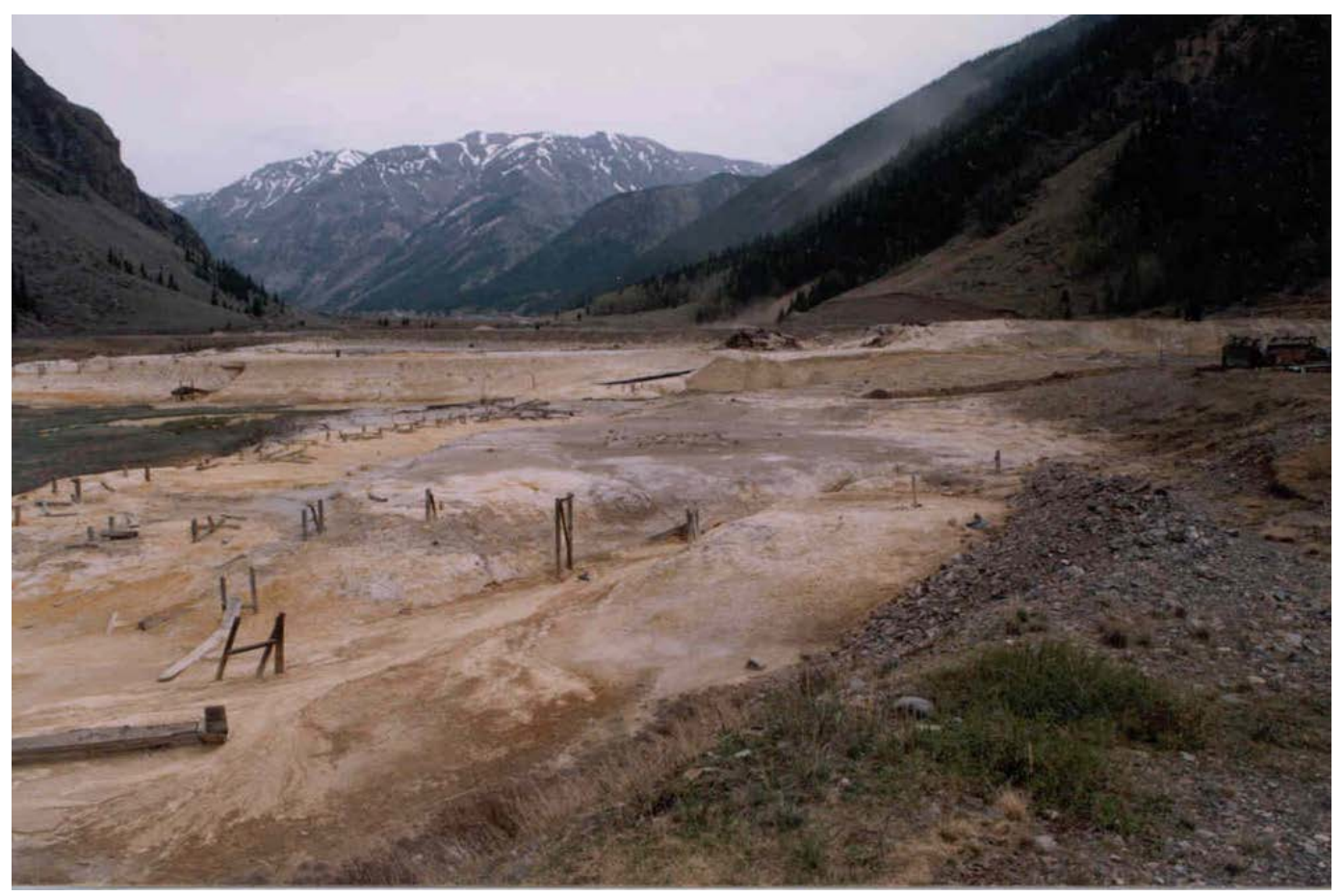

Figure 6 Pride of the West, 1996, before reclamation 


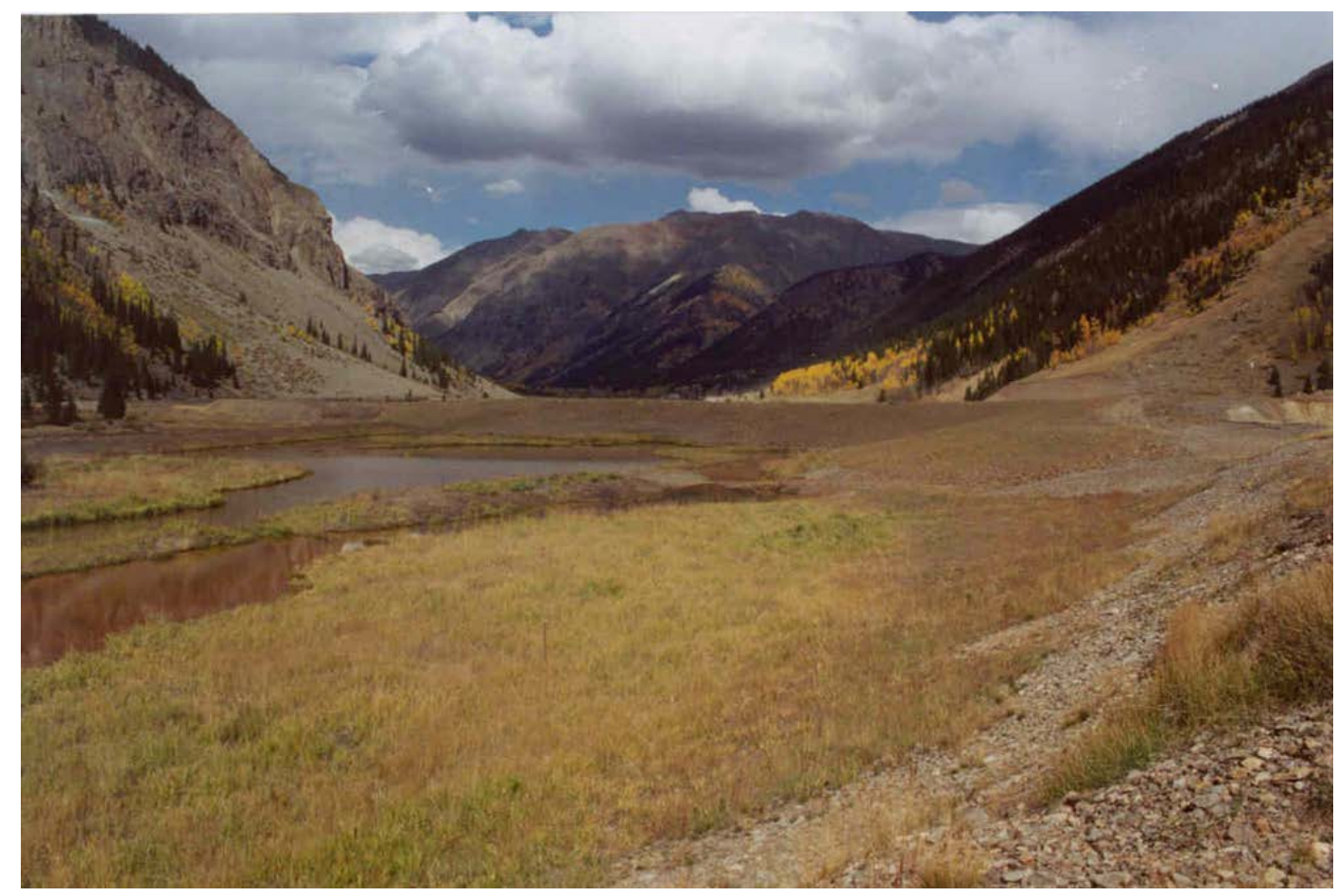

Figure 7 Site location

\section{$4 \quad$ Data}

More than 22 years (1996-present) of recorded flows and zinc concentrations at sampling point A-72 were compiled and analysed. Zinc concentrations have historically been utilised to analyse water quality in the Animas River because the properties of zinc make it an ideal indicator of overall metals loading. A-72 is a long-established monitoring point on the Animas River below the confluences of Cement and Mineral Creeks with comprehensive historical data.

\section{Colorado Department of Public Health and Environment methodology}

The methodology employed to analyse the data was taken directly from the Consent Decree and was designed to account for seasonal fluctuations in streamflow. CDPHE employed this methodology to analyse metals loading in the Animas River during and after SGC's remediation activities and concluded that SGC had met the target and successfully completed its obligations under the Consent Decree. Based upon this, CDPHE released SGC from further obligations and released SGC's US 5 million letter of credit in full.

The headwaters of the Animas River are subject to seasonal fluctuations of flow due to varying climatic factors. When comparing time series concentrations of dissolved metals in surface waters, standard practice is to compare changes in concentrations to variations in streamflow. When the dataset consists of samples collected at many different streamflows, some, or perhaps all, of the variation in concentration could be the result of variation of streamflows and not to changes in upstream loading. By computing a regression equation relating streamflow to concentration, the effect of streamflow on concentration can be taken into account.

To use traditional statistical methods, which are based on assuming normally distributed data, the flow and concentration data at A-72 need to be transformed to account for the log-normal distribution of the data. The applied transformation consisted of taking the natural logarithm of the flow and concentration data. The transformed data can then be evaluated using linear regression analysis. 
The reference period is defined as water quality data collected from 5 September 1991 to 22 May 1996. During this period, the mine was closed, but SGC was operating a water treatment plant that treated discharges from the American Tunnel and, during low flows, the entirety of Cement Creek. The resulting water quality was probably as good as, or better, than natural pre-historic mining levels and became CDPHE's target. Separate regression equations were calculated for those samples on the rising limb of the stream hydrograph and those not on it as shown on Figure 8.

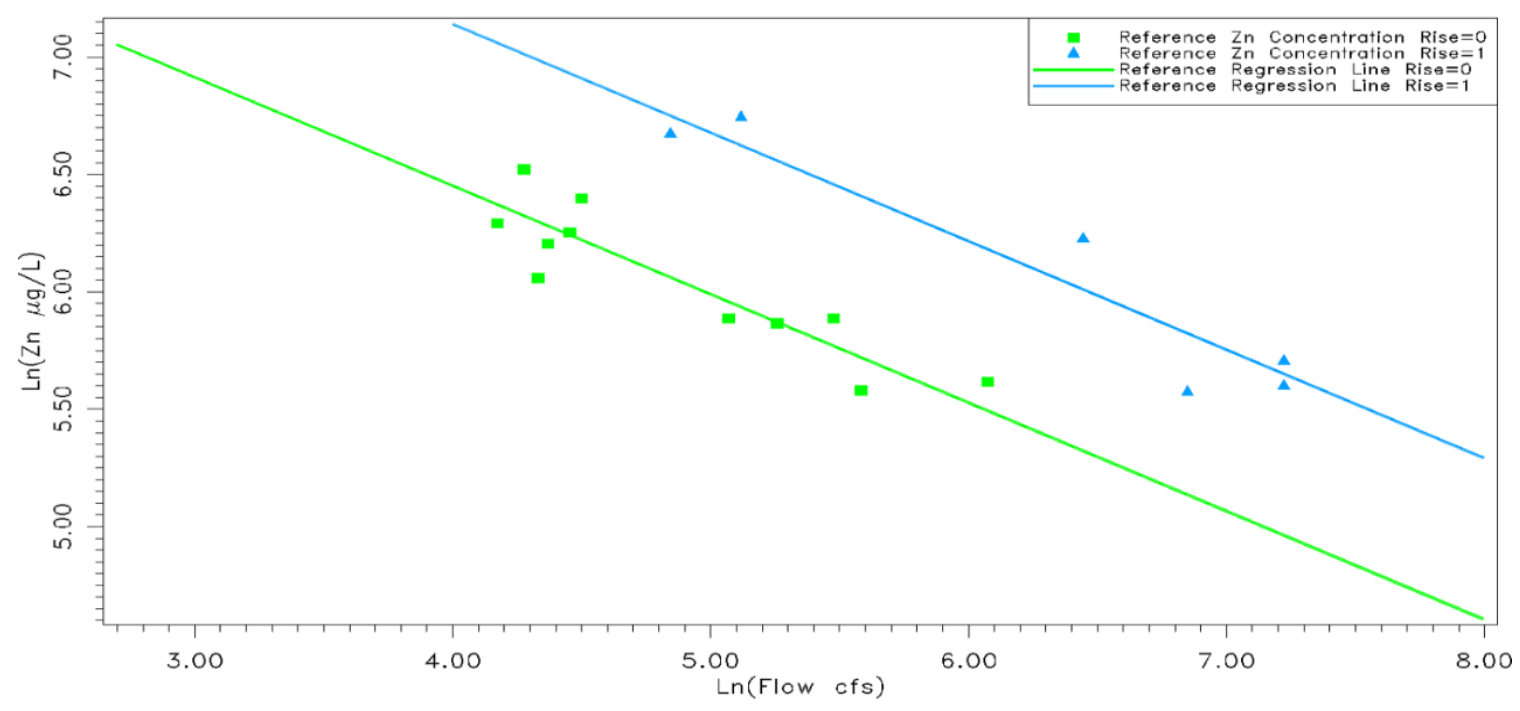

Figure 8 Regression plot reference period

The regression equation (Equation 1) relating the zinc concentration at A-72 to flow during the baseline period is:

$$
\operatorname{Ln}(\mathrm{ZnA}-72)=8.30-0.462 \times \operatorname{In}(\text { flow })+0.697 \times \text { Rise }
$$

where:

$$
\begin{aligned}
& \text { Rise }=1 \text { if on the rising limb of the hydrograph and } 0 \text { otherwise. } \\
& \mathrm{ZnA}-72=\mathrm{e}^{[\ln \{Z \mathrm{ZnA}-72)]} \text {. }
\end{aligned}
$$

To remove the effects of flow and rise on the analysis, the value predicted from the regression equation is subtracted from the natural logarithm of the measured zinc concentration to create a residual. The residual is the distance the observed value deviates from the regression line. The residual contains the variation due to all variables other than flow and rise. The residual is then standardised by dividing by the standard error of the regression. In this way, the magnitude and importance of the residual can be judged (Equation 2):

$$
\text { StR }=(\ln [\text { ZnA-72 Actual }]-\ln [\text { ZnA-72 Pred }]) / \text { StdE }
$$

To evaluate the trends in the data, a running average of length 10 was calculated. Values that descend below the centre line indicate samples where the actual value is better than would be expected based on the baseline relationship and values extending above the line indicate samples where the actual value is worse than would be expected if the conditions were similar to those during the baseline period. The regression analysis simply compares the characteristics of one set of data with another. There is no time variable in the analysis other than the selection of data groupings.

\section{Results of the analysis}

A plot of the running average of the standard residual of the zinc concentration at A-72 over the period of interest is presented in Figure 9. Review of the plot in Figure 9 indicates that the standard residual changes in response to specific anthropomorphic changes to the watershed. The results are discussed in the following paragraphs. 


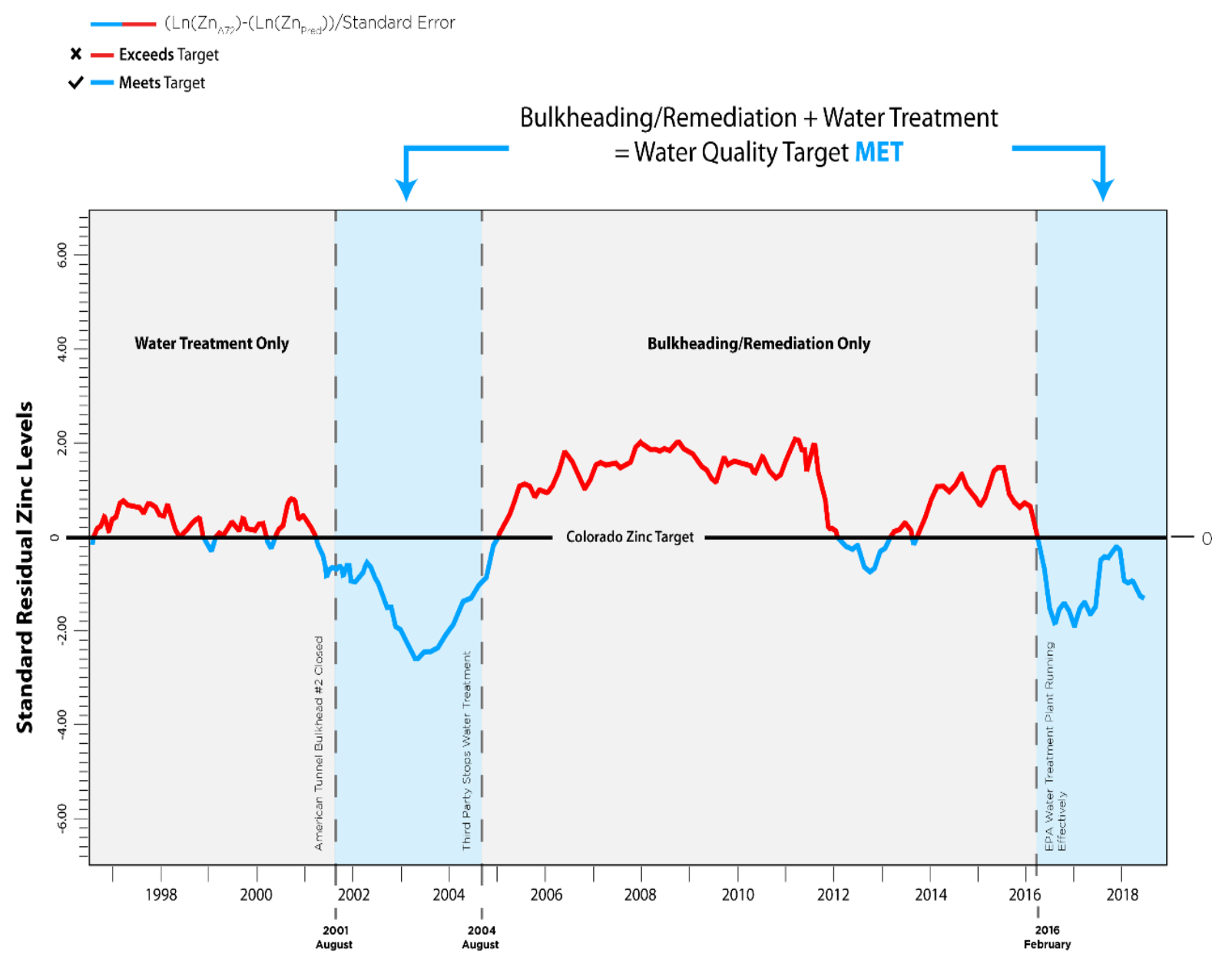

Figure 9 Animas River Standardized zinc residuals

\subsection{June 1996-August 2001: water treatment alone does not achieve target}

SGC commenced the bulkheading and remediation in the summer of 1996 . The most critical component of the endeavour was the construction of American Tunnel bulkhead $\# 1$, which isolated the interior workings of the Sunnyside Mine. The successful isolation of the interior workings was demonstrated in May 2001, when water behind bulkhead \#1 reached confirmed equilibrium. In August 2001, American Tunnel bulkhead \#2 was completed to isolate water inflows from a fracture zone not on SGC's property. Active remediation of mine and process waste was ongoing during this period and any reduction of load resulting from these activities would not yet be evident. A water treatment plant was operated at Gladstone from June 1996 through to August 2001. During this period, CDPHE's target was not met on a regular basis (Figure 9). This demonstrates that one independent aspect of CDPHE's Plan-in this case water treatment-was not enough to result in consistently achieving CDPHE's target.

\subsection{August 2001-August 2004: bulkheading/remediation and water treatment jointly achieve target}

A water treatment plant continued to be operated at Gladstone from August 2001 until August 2004 and the reduction in the zinc standardized residual resulting from the remediation activities was evident in the plot trends. During this period, the target was met (Figure 9). This conclusively demonstrates the success of SGC's bulkheading and remediation and that the target would be met when both aspects, bulkheading and remediation plus water treatment, of CDPHE's plan were in place. 


\subsection{August 2004-August 2015: bulkheading/remediation alone does not achieve target}

Subsequent to an unrelated independent third party ceasing to operate the water treatment plant at Gladstone in August 2004, there was a statistically significant upward trend in zinc residuals at A-72 (Figure 9). Commencing in 2005, CDPHE's target was no longer being achieved.

While SGC's bulkheading and remediation continued to be successful and was improving water quality, the second aspect of CDPHE's plan had been compromised, which resulted in the target generally not being achieved between August 2004 and August 2015. It is interesting to note that even with the negation of the second aspect of CDPHE's plan, SGC's bulkheading and remediation was so successful in improving water quality that the target was met at times during this period. Absent the Gold King blowout, it is possible that the target could have been achieved more often over time as natural groundwater equilibrium evolved.

\subsection{The Gold King blowout}

On 5 August 2015, the EPA released millions of gallons of mine-impacted water, which resulted in a spike in zinc concentrations at A-72. It should be noted that the standard residuals running average methodology causes the impact of the blowout to be reflected on Figure 9 both before and after 5 August 2015. Additionally, this sudden release of pressure resulted in significant alteration of the groundwater flow regime within the mountain.

\subsection{February 2016-present: bulkheading/remediation and water treatment presently jointly achieve target}

The EPA commenced operation of a water treatment plant at Gladstone in October 2015 and the plant was running effectively, but at substantially less than full capacity, by February 2016. Even running the plant at a fraction of its capacity resulted in a statistically significant downward trend in zinc concentrations at A-72, with the target being achieved commencing June 2017 (Figure 9). This again demonstrates the success of SGC's bulkheading and remediation in improving water quality. Today, water quality is better than CDPHE's target. While the blowout resulted in significant alteration of the groundwater flow regime, the data indicates that CDPHE's target would be met consistently going forward if the EPA were to elect to run the water treatment plant at full capacity.

\section{Conclusion}

The analysis of zinc loading using CDPHE's methodology at A-72 from 1996 through to the present conclusively demonstrates that SGC's bulkheading and remediation was successful and improved water quality by substantially reducing acid rock drainage and metals loading in the Animas River and its tributaries. Whenever both aspects of CDPHE's plan were in place, both prior to and after the Gold King blowout, CDPHE's target was met. Each aspect of CDPHE's plan-SGC's bulkheading and remediation and the operation of a water treatment plant at Gladstone-played a key role in the target being achieved and the improvement of water quality. Although the Gold King blowout significantly altered the existing groundwater flow regime, CDPHE's target is being met today as a combined result of SGC's bulkheading and remediation and the EPA operating its treatment plant at a fraction of capacity. 


\section{Appendix $1 \quad$ SGC bulkheading and remedial activities}

1. Eureka tailings: SGC removed 85,630 cubic meters of historic finely ground tailings, which are more geochemically active, from the banks and floodplain of the Animas River and its tributaries and relocated them to the Mayflower Impoundments.

2. American Tunnel mine waste and tailings: $S G C$ removed 72,500 tonnes of mostly historic mine waste and tails.

3. Longfellow-Koehler project: SGC opened a caved adit and removed 24,500 cubic meters of mine waste and pond sediments, consolidated other waste to reduce footprint, added neutralising materials to the area, covered the area with overburden, seeded, and constructed surface water diversion to divert upland flow around the site.

4. Boulder Creek tailings: SGC removed 4,400 cubic meters of tailings from the Boulder Creek and Animas River flood plain.

5. Pride of the West Tailings: SGC excavated 64,250 cubic meters of historic tailings and relocated 35,500 cubic meters to an onsite tailings impoundment and the remainder to the Mayflower tailings impoundment \#4. SGC conducted a geotechnical study, installed a toe drain, and contoured the slope. SGC capped the impoundment with overburden, fertilised, and seeded. SGC partially rebuilt and planted a wetland.

6. Lime injection: SGC injected approximately 590,000 kilograms of hydrated lime into the interior workings of the Sunnyside Mine to increase alkalinity.

7. Gold Prince Mine waste and tailings: SGC installed two closure bulkheads, relocated historic tails and ash piles into lined containment within a consolidated waste pile that was relocated away from stream flows, covered removal areas with overburden, and seeded.

8. Ransom adit drainage: SGC opened the caved in adit, designed and installed a bulkhead to eliminate drainage, graded the portal area, and seeded.

9. Mayflower hydraulic controls: SGC designed and installed three interception structures to capture and transport stormwater and groundwater around Mayflower impoundment \#1 and the Mayflower Mill area to prevent contact and infiltration with tailings and waste rock.

10.Sunnyside basin: SGC placed 183,500 cubic meters of clean fill to cover the Lake Emma subsidence area and to create positive drainage, contoured the area, and seeded.

11.American Tunnel portal: SGC removed surface facilities, constructed a diversion ditch, stabilised the bank of Cement Creek, re-contoured, and seeded.

12.Mogul adit and Koehler Tunnel bulkheads: SGC funded the placement of bulkheads in the Mogul Adit and Koehler Tunnel.

13.Mayflower passive treatment wall: SGC constructed a passive treatment wall for groundwater exiting a wetland near the southwest corner of the historic lower deposits in tailings impoundment \#4.

14.Power plant tailings: SGC picked up tailings previously reclaimed along the Animas River in the vicinity of the old power plant and consolidated these into TP4.

15.Bulkhead installation: with oversight and approval of all relevant agencies, SGC installed a series of engineered concrete bulkheads to isolate the Sunnyside Mine workings from other workings in the area and to prevent water flow from the Sunnyside Mine workings into the Animas River. The bulkheads were always expected to return the local water table towards its natural, pre-mining level. 


\section{References}

Besser, JM \& Brumbaugh, WG 2007, 'Status of Stream Biotic Communities in Relation to Metal Exposure', in SE Church, P von Guerard \& SE Finger (eds), Integrated Investigation of Environmental Effects of Historical Mining in the Animas River Watershed, San Juan County, Colorado, US Geological Survey, Reston.

Church, SE, von Guerard, P \& Finger, SE 2007, Integrated investigations of environmental effects of historical mining in the Animas River watershed, San Juan County, Colorado, U.S. Geological Survey, Reston.

Jones, WR 2007, 'History of Mining and Milling Practices and Production in San Juan County, Colorado, 1871-1991', in SE Church, P von Guerard \& SE Finger (eds), Integrated Investigation of Environmental Effects of Historical Mining in the Animas River Watershed, San Juan County, Colorado, US Geological Survey, Reston.

Sunnyside Gold Corporation v Colorado Water Quality Control Division of the Colorado Department of Public Health and Environment, case no. 94-CV-5450 (May 8, 1998).

US Geological Survey 2007, Environmental Effects of Historical Mining in the Animas River Watershed, Fact Sheet 2007-3051, Colorado. 
